\title{
Exposure to plastic surgery during undergraduate medical training: A single-institution review
}

\author{
Ryan E Austin MD ${ }^{1}$, Kyle R Wanzel MD MEd FRCSC ${ }^{1,2}$
}

RE Austin, KR Wanzel. Exposure to plastic surgery during undergraduate medical training: A singleinstitution review. Plast Surg 2015;23(1):43-47.

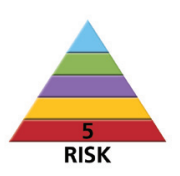

BACKGROUND: Applications to surgical residency programs have declined over the past decade. Even highly competitive programs, such as plastic surgery, have begun to witness these effects. Studies have shown that early surgical exposure has a positive influence on career selection. OBJECTIVE: To review plastic surgery application trends across Canada, and to further investigate medical student exposure to plastic surgery. METHODS: To examine plastic surgery application trends, national data from the Canadian Resident Matching Service database were analyzed, comparing 2002 to 2007 with 2008 to 2013. To evaluate plastic surgery exposure, a survey of all undergraduate medical students at the University of Toronto (Toronto, Ontario) during the 2012/2013 academic year was conducted.

RESULTS: Comparing 2002 to 2007 and 2008 to 2013, the average number of national plastic surgery training positions nearly doubled, while first-choice applicants decreased by $15.3 \%$. The majority of Canadian academic institutions experienced a decrease in first-choice applicants; $84.7 \%$ of survey respondents indicated they had no exposure to plastic surgery during their medical education. Furthermore, $89.7 \%$ believed their education had not provided a basic understanding of issues commonly managed by plastic surgeons. The majority of students indicated they receive significantly less plastic surgery teaching than all other surgical subspecialties. More than $44 \%$ of students not considering plastic surgery as a career indicated they may be more likely to with increased exposure. CONCLUSION: If there is a desire to grow the specialty through future generations, recruiting tactics to foster greater interest in plastic surgery must be altered. The present study suggests increased and earlier exposure for medical students is a potential solution.

Key Words: Internship and residency; Medical education; Plastic surgery

$\mathrm{P}_{\mathrm{i}}^{\mathrm{i}}$ lastic surgery has long been considered to be a highly desirable and highly competitive specialty $(1-3)$. Due to its popularity with applicants, plastic surgery residency programs have historically had among the lowest success rates for applicants in both Canada and the United States (2-4). In fact, a recent article by Nagarkar et al (2) labelled plastic surgery "the most elusive residency program". However, the status quo appears to be changing as we transition into a new generation of medical trainees, 'Generation Y'. Born between 1982 and 2005, Generation Y has been raised within a closely supported environment in which they are sheltered from failure, and where teamwork has replaced hierarchy (5). All of these factors differ greatly from traditional surgical training. Although this concept of a 'generational gap' is not novel - for example, Rohrich (6) highlighted similar issues in a discussion on the difficulties of training surgeons from Generation X (born 1961 to 1981) - today's medical students appear to be less interested in surgical careers than ever before, instead opting for 'lifestyle' specialties that allow a greater work-life balance (7-9). Undergraduate medical education programs have perpetuated this

\section{L'exposition à la chirurgie plastique pendant la formation générale en médecine : une analyse monocentrique}

HISTORIQUE : Les candidatures aux programmes de résidence en chirurgie ont diminué depuis dix ans. Même les programmes hautement compétitifs, comme la chirurgie plastique, ont commencé à en ressentir les effets. Les études ont démontré que l'exposition rapide à la chirurgie a une influence positive sur le choix de carrière.

OBJECTIF : Examiner les tendances de candidature en chirurgie plastique au Canada, de même que l'exposition des étudiants en médecine générale à la chirurgie plastique.

MÉTHODOLOGIE : Pour examiner les tendances de candidature en chirurgie plastique, les chercheurs ont analysé les données nationales tirées de la base de données du Service canadien de jumelage des résidents en comparant les données de 2002 à 2007 à celles de 2008 à 2013. Pour évaluer l'exposition à la chirurgie plastique, ils ont sondé tous les étudiants en médecine de premier cycle à l'université de Toronto, en Ontario, pendant l'année universitaire 2012-2013.

RÉSULTATS : Si on compare 2002 à 2007 et 2008 à 2013, le nombre moyen de postes nationaux de formation en chirurgie plastique a pratiquement doublé, tandis que le taux de candidats qui en font leur premier choix a diminué de $15,3 \%$. La majorité des établissements universitaires canadiens ont observé une diminution des candidats qui en font leur premier choix. Ainsi, $84,7 \%$ des répondants au sondage ont indiqué qu'ils n'avaient pas été exposés à la chirurgie plastique pendant leur formation en médecine. De plus, 89,7\% trouvaient que leur formation ne leur permettait pas de comprendre les problèmes de base que gèrent régulièrement les plasticiens. La majorité des étudiants ont indiqué recevoir beaucoup moins d'enseignement en chirurgie plastique que dans toutes les autres surspécialités chirurgicales. Plus de $44 \%$ des étudiants qui n'envisageaient pas faire carrière en chirurgie plastique ont indiqué qu'ils l'envisageraient peut-être davantage s'ils y étaient plus exposés. CONCLUSION : $\mathrm{Si}$ on veut faire croître la spécialité au sein des prochaines générations, il faudra modifier les tactiques de recrutement pour stimuler l'intérêt envers la chirurgie plastique. D'après la présente étude, l'exposition accrue et plus rapide des étudiants en médecine pourrait faire partie des solutions.

decline by increasing enrollment and modifying their curricula in efforts to attract students to careers in primary care $(10,11)$.

In reality, it is time to admit that the landscape for plastic surgery training in Canada is also changing. In 2002, there were nine plastic surgery training positions offered nationwide, attracting 27 first-choice applicants from 1117 total Canadian Resident Matching Service (CaRMS) registrants (2.4\%) (4). Compare this with 2013, in which 26 residency positions were offered, and 48 of a possible 2747 CaRMS applicants selected plastic surgery as a first-choice discipline (1.8\%) (4). Although this $0.6 \%$ decrease in applicants may appear to be inconsequential at first glance, it equates to nearly 17 fewer applicants per year, corresponding to $65 \%$ of the current national training capacity. Still, the plastic surgery community has largely ignored this shifting tide, choosing to believe the specialty immune from this ebb of surgical interest due to its 'elite' training program status.

Questions have also been raised as to the quality of plastic surgery applicants, and whether this also has declined over recent years. This concern has been raised previously in the general surgery literature

${ }^{1}$ Division of Plastic $\mathbb{E}$ Reconstructive Surgery, Department of Surgery, University of Toronto; ${ }^{2}$ Division of Plastic Surgery, St Joseph's Health Centre, Department of Surgery, University of Toronto, Toronto, Ontario

Correspondence: Dr Ryan E Austin, Division of Plastic $\mathcal{G}$ Reconstructive Surgery, Department of Surgery, University of Toronto, Stewart Building, 149 College Street, 5th Floor, Toronto, Ontario M5T 1P5. Telephone 416-978-2623, fax 416-978-3928,

e-mail ry.austin@mail.utoronto.ca 
TABLE 1

Average percentage of graduating class selecting plastic
surgery as the first-choice residency program in the
Canadian Resident Matching Service database, according
to academic institution

\begin{tabular}{lcccc}
\hline & \multicolumn{3}{c}{$\begin{array}{c}\text { Mean percentage of students } \\
\text { selecting plastic surgery as }\end{array}$} & \\
\cline { 2 - 4 } Undergraduate medical & \multicolumn{3}{c}{ first-rank choice, \% of class } & \\
\cline { 2 - 4 } school & $\mathbf{2 0 0 2 - 2 0 0 7}$ & $\mathbf{2 0 0 8 - 2 0 1 3}$ & Change & P \\
\hline University of Alberta & 1.367 & 2.283 & 0.916 & 0.080 \\
Memorial University & 1.867 & 2.500 & 0.633 & 0.534 \\
Dalhousie University & 2.217 & 2.750 & 0.533 & 0.523 \\
University of Ottawa & 1.067 & 1.417 & 0.350 & 0.355 \\
McMaster University & 1.617 & 1.750 & 0.133 & 0.832 \\
Queen's University & 2.083 & 2.183 & 0.100 & 0.873 \\
Western University & 2.400 & 2.283 & -0.117 & 0.825 \\
University of Manitoba & 1.750 & 1.583 & -0.167 & 0.785 \\
University of Saskatchewan & 2.633 & 2.450 & -0.183 & 0.887 \\
University of Calgary & 3.150 & 2.683 & -0.467 & 0.531 \\
University of British Columbia & 3.033 & 2.233 & -0.800 & 0.345 \\
McGill University & 3.800 & 2.683 & -1.117 & 0.069 \\
University of Toronto & 3.167 & 1.633 & -1.534 & $0.006^{*}$ \\
\hline
\end{tabular}

*Statistically significant (ie, $P<0.05$ ).

and, although no significant difference was found, the impetus for this study suggests that these concerns do exist (12). In Canadian plastic surgery, this viewpoint may be supported by three recent unmatched plastic surgery training positions across Canada (in 2008 [1], 2010 [1], and 2011 [1]), which had never happened in the past (4). Has the quality of applicants diminished to the point in which programs would rather leave a residency position vacant than select a potential candidate?

Interestingly, at our institution, we noted that fewer students from our affiliated undergraduate medical school were applying for residency positions in plastic surgery, whereas other programs appeared to have an abundance of applicants. How could it be that some schools were fostering an interest in plastic surgery at a time when Generation Y (1982 to 2005) - the modern era of medical students - was no longer interested in the surgical lifestyle (5)?

Our hypothesis was that students at our institution were not receiving sufficient exposure to plastic surgery during their training to cultivate an interest in the specialty. The objectives of the present study were: to perform a more detailed analysis of recent trends in plastic surgery applications across Canada; and to determine the amount of exposure that medical students at our institution receive during their undergraduate medical education.

\section{METHODS}

To examine the recent trends in plastic surgery applications across Canada, application data were accessed through the CaRMS online database (2002 to 2013 inclusive) (4). At the time of study completion, these were the only years publically available for review. Of the 17 undergraduate medical schools across Canada, four institutions did not have data available for the entire time period analyzed and were, therefore, excluded. The remaining 13 programs were included in the analysis.

Analysis for the present study focused on first-choice applicants to plastic surgery. These are final-year medical students who have ranked a plastic surgery program as their overall first choice in the CaRMS match. Students who had ranked plastic surgery as a second choice or lower were excluded from the analysis.

The application data were divided into two groups, those graduating in 2002 to 2007 and those graduating 2008 to 2013. Averages from these six-year time intervals were compared to determine percent difference. This division not only conveniently separates the data in half, but also approximates the temporal transition from Generation X to Generation
Y (ie, a Generation Y student born in 1982 would be graduating from medical school no earlier than 2008). Comparisons were made using a two-tailed Student's $t$ test with statistical significance set at $\mathrm{P} \leq 0.05$.

To determine the amount of exposure that medical students at the Univesrity of Toronto (Toronto, Ontario) receive during their undergraduate medical education, the authors conducted a survey-based assessment of all undergraduate medical students enrolled in the Faculty of Medicine during the 2012/2013 academic year. A 19-question survey was developed using the online survey tool, SurveyMonkey (Survey Monkey Inc, USA) on exposure to plastic surgery and student perceptions of the specialty. To assure content validity, the survey was reviewed by three academic plastic surgeons affiliated with the University of Toronto before data collection.

Research ethics approval was obtained from the Office of Research and Innovation at the University of Toronto, and the survey was distributed to the students via the Undergraduate Medical Education Office at the University of Toronto. The survey was available for completion between February and April 2013 for a total period of eight weeks. Students were sent a recruitment e-mail through a secure internal server, which contained an introductory letter and a link to the online survey. Students were deemed to consent to participation in the research study if they completed the survey. Reminder e-mails were sent to the students at the two- and five-week time points following initial contact. The survey was closed at the eight-week time point. As incentive for completing the survey, students were offered the opportunity to enter a random draw for one of three $\$ 20$ gift cards.

Results of the survey were analyzed and are presented as a percentage of respondents for each question. The response rates of preclinical students (first/second year) and clinical students (third/fourth year) are presented in addition to the overall results where appropriate.

\section{CaRMS data analysis}

\section{RESULTS}

Comparing 2002 to 2007 and 2008 to 2013, the average annual number of residency training positions increased by 11.2 positions, while the average number of first-choice applicants to plastic surgery has decreased by $15.3 \%$. National data from the CaRMS residency match on student selection of plastic surgery as a first-choice residency program is presented in Table 1. Six schools experienced an increase in average first-choice applications to plastic surgery among their graduating class, while seven schools experienced a decrease. The University of Toronto had the largest decline in average applications $(-1.534 \% ; \mathrm{P}=0.006)$, which was also the only statistically significant result in the analysis. Two programs (McGill University [Montreal, Quebec] and University of Alberta [Edmonton, Alberta]), however, also experienced a change in the number of applicants that approached significance.

\section{Survey}

Demographics: Overall, 354 of 989 (35.8\%) students enrolled in the four-year undergraduate medical program at the University of Toronto responded to the survey. When analyzed per year of study, response rates were considerably higher for first- $(50.6 \%)$ and second- $(47.1 \%)$ year students compared with third- $(22.7 \%)$ and fourth- $(20.1 \%)$ year students. One hundred thirty-five $(38.1 \%)$ respondents were male while 217 (61.3\%) were female. With regard to the highest level academic degree achieved before entering medical school, $60.7 \%$ of respondents had a Bachelor's degree, $31.1 \%$ had a Master's degree, $6.2 \%$ had a Doctoral decree and $2.0 \%$ had no academic degree. The mean age of the respondents was 25.0 years.

Career selection and interest in plastic surgery: The students were asked to indicate which residency programs they were considering as potential future career options (Figure 1). There was no limit to the number of career options that they could select. The top three choices were internal medicine (56.2\%), family medicine $(52.8 \%)$ and surgery $(40.1 \%)$. A larger proportion of first- and second-year respondents $(47.0 \%)$ indicated a potential interest in surgery compared with thirdand fourth-year students (22.8\%). 


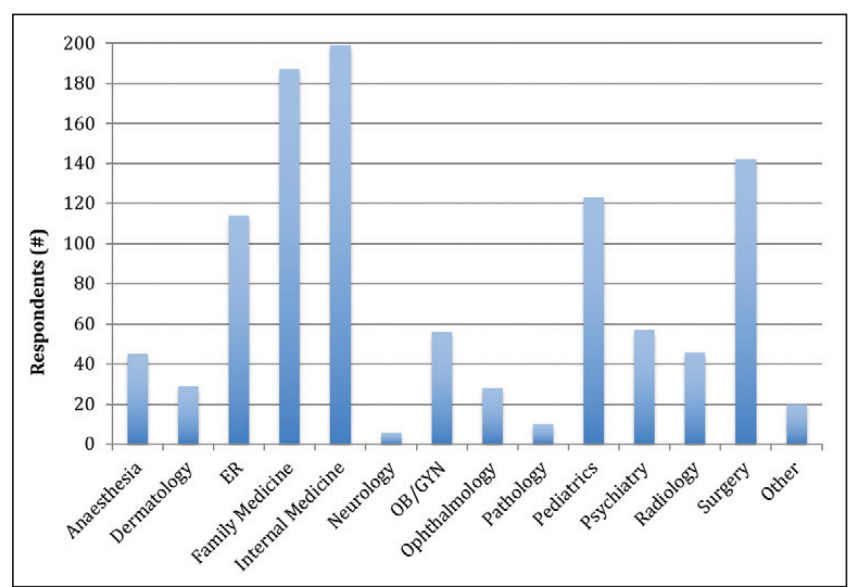

Figure 1) Histogram illustrating the future career paths being considered by University of Toronto (Toronto, Ontario) medical student respondents at the time of the survey (respondents were able to select as many career choices as they desired)

Respondents were asked to rate the importance of a variety of factors when selecting a career. Students identified lifestyle, amount of patient interaction, personality of staff members and job availability as the most important factors in career selection. Students were then asked to predict how a career in plastic surgery would meet their anticipated career needs in these same domains. The majority of students believed that a career in plastic surgery would be well suited to their needs in the areas of income potential, manual skill requirement and variety of procedures. The likelihood of matching to a residency position and job availability were considered to be the major drawbacks of the specialty (Figure 2). Only 6.3\% of respondents indicated that plastic surgery met their needs either well or very well with regard to likelihood of matching to a residency position, with the majority (56.5\%) claiming it was a poor match.

When asked specifically about a career in plastic surgery, $131 \mathrm{stu}$ dents (39.6\% overall; $43.6 \%$ of first/second year students; $29.5 \%$ of third/fourth year students) had considered the specialty as a potential career at some point during their medical education. Of the 200 (60.4\%) students who had not considered a career in plastic surgery, $6.2 \%$ $(8.46 \%$ first/second year; $1.52 \%$ third/fourth year) believed they would definitely be more likely to consider plastic surgery as a career with increased exposure during their medical training. An additional $38.3 \%$ (40.77\% first/second year; $33.33 \%$ third/fourth year) indicated they may be more likely to consider plastic surgery with increased exposure.

Exposure to plastic surgery: Of all students surveyed, $276(84.7 \%$ overall; $98.3 \%$ first/second year; $51.1 \%$ third/fourth year) indicated that they had received no formal plastic surgery teaching during their medical training. Among the $15.3 \%$ of students who stated they had received formal exposure to plastic surgery, $42.6 \%$ claimed to have a more positive impression of the field as a direct result of their exposure.

When asked to compare the amount of plastic surgery teaching received as part of the teaching curriculum with other surgical specialties, the majority of students indicated that they received significantly less plastic surgery teaching than all other surgical subspecialties (Figure 3).

With regard to plastic surgery exposure outside of the classroom, respondents were asked what impact media (ie, television and film) has had on their impression of the specialty: $50.8 \%$ of respondents stated that media had a negative impact on their perceptions of plastic surgery as a career; $10.5 \%$ identified that media exposure resulted in a more positive perception of plastic surgery, while $38.7 \%$ reported no impact. Knowledge of plastic surgery: Overall, 280 students (89.7\% overall; $96 \%$ first/second year; $73.6 \%$ third/fourth year) believed that their medical education had not sufficiently provided a basic understanding of the common patient issues managed by plastic surgeons.

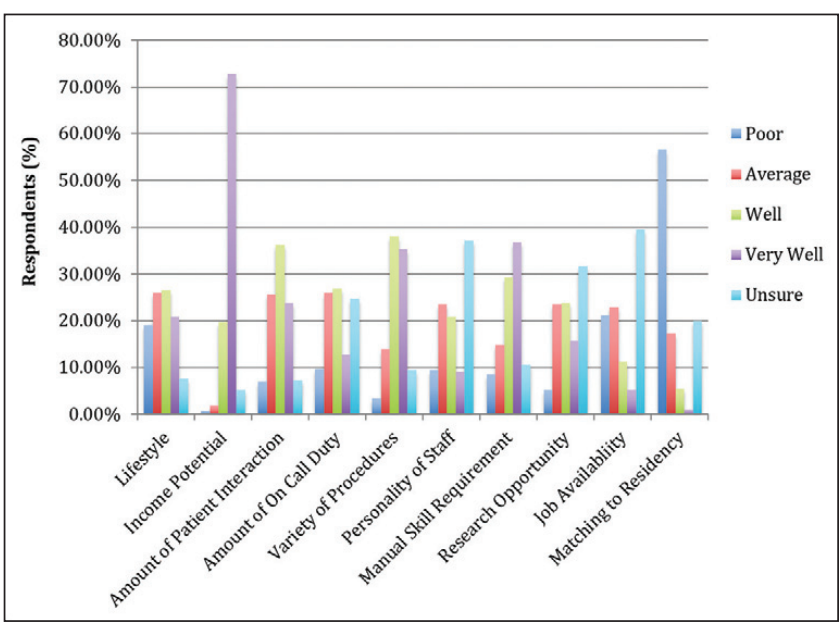

Figure 2) University of Toronto (Toronto, Ontario) students' perceptions of how a career in plastic surgery would meet their needs in a variety of work- and life-related domains

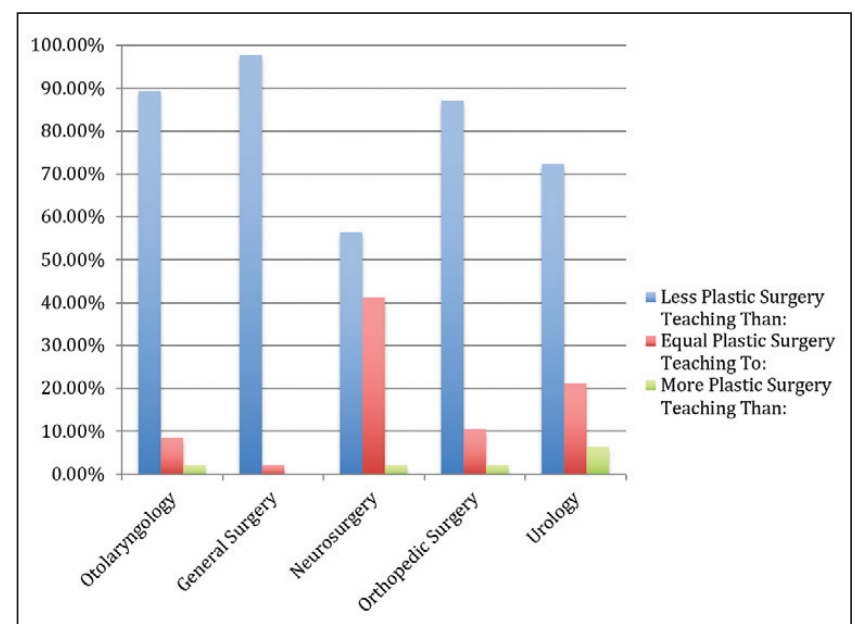

Figure 3) Histogram illustrating University of Toronto (Toronto, Ontario) medical students' perceptions of the amount of formal teaching time dedicated to the surgical specialties compared with plastic surgery

\section{DISCUSSION}

According to data from CaRMS, there has been an overall decline in interested applicants applying to plastic surgery. Although the number of students enrolled in medical school and the number of plastic surgery training positions have more than doubled over the past decade, a smaller percentage of medical graduates are interested in pursuing a career in plastic surgery. Although some institutions experienced an increase in average percentage of applicants, the reality is the majority of medical schools faced a decrease in first-choice applicants (Table 1). Furthermore, the programs that did experience a decline in firstchoice applicants are the largest medical schools according to enrollment, accounting for $61.3 \%$ of students in the programs studied (13). The fact that only one school showed a statistically significant decline should not detract from the overall results presented. Despite the fact that the University of Toronto is second largest medical school in Canada, these results are subject to a lack of power given that plastic surgery is a small specialty dealing with a small number of applicants. We believe it is becoming clear that the Canadian medical education system is failing to effectively foster an interest in plastic surgery as a viable career choice.

Unfortunately, nowhere has this effect been as apparent as our institution. With the largest plastic surgery program in Canada, we believed our institution had the potential to provide an extensive opportunity 
for medical students to develop an interest in the specialty. However, with an average decrease in first-choice applicants of $-1.534 \%$, the University of Toronto had the largest decrease among all institutions reviewed (Table 1).

Most would likely attribute this decreased interest in plastic surgery to a generalized decline in surgical interest $(9,10,14)$. The results of our survey suggest this may not be the case. Approximately $40.1 \%$ of respondents claimed to be considering a surgical subspecialty as a career option (Figure 1). Although it is easy to place the onus on the trainees, the issue may be that the surgical specialties are failing to convert consideration into genuine interest. A study by Scott et al (15) found that medical students interested in surgery were among the most stable when it came to residency choice because $>70 \%$ of students entering a surgical program had selected surgery in their top three career choices on entry to medical school. Therefore, plastic surgery may be best-suited focusing recruitment efforts on this careermalleable, surgically inquisitive group, which has a higher probability of continuing on to a surgical career.

One hurdle impeding efforts to increase plastic surgery interest is the pervasive belief that it is nearly impossible to match to a plastic surgery residency position (Figure 2). While it may appear incomprehensible for a student to disregard a career based on this factor alone, the truth is that we are dealing with a new generation of medical trainees. The modern medical student comes from the generation labelled 'Generation Y', which has been praised for participation while being continually sheltered from failure $(5,16)$. These students may consider the CaRMS match statistics and hear the rumours of futility, in the end deciding that they would rather avoid the specialty than risk possible rejection. By taking strides to make the specialty appear more inviting and attainable, we will certainly not drive away those interested in plastic surgery, but may attract potential applicants. It would be a shame to lose wellqualified applicants to other specialties simply because of a perceived difficulty in obtaining a residency position. The onus is squarely on our specialty to rebrand itself, focusing more on positive aspects of the specialty to entice the next generation of surgeons.

The other major hurdle, which we believe to be the most important factor, is inadequate exposure. Exposure to surgical specialties early in medical training has a positive influence on career choice $(11,17,18)$. If we are to convert the surgically inquisitive first- or second-year student into someone actively pursuing a career in plastic surgery, we need to foster that interest early on. While some would argue that recruitment efforts should be focused on students in their clinical years, we must remember that the third-year student we are trying to convince to enter plastic surgery was very recently a second-year student. By exposing these students earlier in their medical education, we stand a better chance at stimulating interest in plastic surgery. Interestingly, the results of our survey support this position because a greater percentage of firstand second-year students (43.6\% versus $29.5 \%$ ) not only claimed to have considered a career in plastic surgery, but believed that more exposure to the specialty would influence their consideration of plastic surgery as a career.

Too often, third- and fourth-year students on plastic surgery rotations will say 'If only I had known about plastic surgery sooner'. In fact, at our institution, these students are correct; they have no exposure to plastic surgery until relatively late in their education. According to the curriculum at our institution, there are a total of $2 \mathrm{~h}$ of plastic surgery teaching in the four-year program, with both lectures given during the eight-week surgical clerkship rotation in the third year. There is also no mandatory plastic surgery rotation during the clinical clerkship years. This is drastically less lecture time and clinical exposure time compared with the other surgical specialties, all of which have one week (or more) devoted to their specialty during first or second year, and clerkship rotations devoted to their specialty in the third or fourth year curricula. This discrepancy is clearly recognized by the students (Figure 3). Therefore, it comes as no surprise that $84.7 \%$ of respondents stated they had no formal exposure to plastic surgery during their medical education.
Medical schools with increased exposure to plastic surgery through their undergraduate curriculum have been shown to have a larger proportion of their graduating classes applying to plastic surgery (19). Different methods of increased exposure have shown varying levels of success, including formal teaching curricula (20), weekend programs (21), student-led surgical interest groups $(22,23)$, shadowing opportunities $(24)$ and mentorships $(17,25)$. Some studies have even gone so far as to suggest increasing surgical exposure to high school and college students as part of an effort to increase surgical interest (17). At the time of the present study, our institution has begun to develop two separate programs to foster interest in plastic surgery: a plastic surgery interest group that meets periodically throughout the academic year; and a summer surgical exposure program developed for interested students that runs between the first and second year of medical school. It will be very interesting to study and compare the CaRMS data over the next several years to ascertain the effectiveness of these programs, however, we must continue to develop novel methods, and borrow successful concepts from other specialties, to increase interest in plastic surgery.

Importantly, and supporting our efforts, the students believe that increasing exposure would have an effect on their likelihood of considering plastic surgery as a career. The fact that $>44 \%$ of students not considering plastic surgery as a career indicated that they may be more likely to do so with increased exposure should be sufficient proof that we need to develop a greater presence in the undergraduate medical school. If we were able to attract even a fraction of this population, it could significantly impact our institution's first-choice application rate, thus increasing the national pool of plastic surgery applicants and benefitting the specialty as a whole. Based on the $42.6 \%$ of students with plastic surgery exposure who believed their exposure led to a more positive impression of the field, it is not hard to believe that increasing exposure would increase interest in the field.

The present study was not without limitations. As a single-institution evaluation, these results may not apply to students at other academic institutions. Our survey response rate of $35.8 \%$, although acceptable given the population, does put the results at risk of nonresponse bias, especially given that the majority of respondents were first- and second-year students. Finally, it is possible that the online survey format was not the most effective method to ascertain the opinions of survey respondents, given the highly individual nature of student educational experiences in medical school. Potential next steps for the present study would be to review plastic surgery exposure at academic institutions across the country and administer the survey to these students to examine how they may differ from these results. Furthermore, the development of a qualitative component to this survey using a semistructured interview process may provide more insight into this topic.

\section{CONCLUSION}

Plastic surgery is a relatively small surgical specialty that has prided itself on attracting the highest-quality applicants to its residency training programs. Unfortunately, changes in the landscape of medical education in Canada have led to a decline in the number of applicants to the specialty. Although multifactorial in nature, we believe that insufficient, ineffective and untimely exposure to the specialty is driving this decline. To our knowledge, the present study was the first to examine the perceptions of the students themselves on their plastic surgery exposure. If we hope to grow and improve our specialty through future generations, we must alter our recruiting tactics to foster an interest in plastic surgery, which starts with early and more comprehensive plastic surgery exposure for our medical trainees.

DISCLOSURES: The authors have no financial disclosures or conflicts of interest to declare. 


\section{REFERENCES}

1. Harper JG, Given KS, Pettitt B, Losken A. The independent plastic surgery match. Ann Plast Surg 2011;66:568-71.

2. Nagarkar P, Pulikkottil B, Patel A, Rohrich RJ. So you want to become a plastic surgeon? What you need to do and know to get into a plastic surgery residency. Plast Reconstr Surg 2013;131:419-22.

3. Rogers CR, Gutowski KA, Rio A, et al. Integrated plastic surgery residency applicant survey: Characteristics of successful applicants and feedback about the interview process. Plast Reconstr Surg 2009;123:1607-17.

4. Canadian Resident Matching Service. CaRMS Data \& Reports. <www.carms.ca/en/data-and-reports> (Accesed February 16, 2014).

5. Eckleberry-Hunt J, Tucciarone J. The challenges and opportunities of teaching "Generation Y." J Grad Med Educ 2011;3:458-61.

6. Rohrich RJ. Training the Generation X plastic surgeon: Dispelling the myths? Plast Reconstr Surg 2001;108:1733-4.

7. Marschall JG, Karimuddin AA. Decline in popularity of general surgery as a career choice in North America: Review of postgraduate residency training selection in Canada, 1996-2001. World J Surg 2003;27:249-52.

8. Melnyk M, Nelson H, Mickelson J, MacNeily AE. Trends in matching to urology residency in Canada: Are we becoming noncompetitive? J Surg Educ 2013;70:537-43.

9. Minor S, Poenaru D, Park J. A study of career choice patterns among canadian medical students. Am J Surg 2003;186:182-8.

10. Polk HC. The declining interest in surgical careers, the primary care mirage, and concerns about contemporary undergraduate surgical education. Am J Surg 1999;178:177-9.

11. Erzurum VZ, Obermeyer RJ, Fecher A, et al. What influences medical students' choice of surgical careers. Surgery 2000;128:253-6.

12. Cofer JB, Biderman MD, Lewis PL, et al. Is the quality of surgical residency applicants deteriorating? Am J Surg 2001;181:44-9.

13. The Association of Faculties of Medicine of Canada. Canadian Medical Education Statistics 2013. <www.afmc.ca/pdf/Cmes2013 Information.pdf> (Accessed February 16, 2014).
14. Scott I, Gowans M, Wright B, Brenneis F. Determinants of choosing a career in surgery. Med Teach 2011;33:1011-7.

15. Scott I, Gowans M, Wright B, Brenneis F. Stability of medical student career interest. Acad Med 2012;87:1260-7.

16. Schlitzkus LL, Schenarts KD, Schenarts PJ. Is your residency program ready for Generation Y? J Surg Educ 2013;67:108-11.

17. Kozar RA, Lucci A, Miller CC, et al. Brief intervention by surgeons can influence students toward a career in surgery. J Surg Res 2003;111:166-9.

18. Drolet BC, Sangisetty S, Mulvaney PM, Ryder BA, Cioffi WG. A mentorship-based preclinical elective increases exposure, confidence, and interest in surgery. Am J Surg 2014;207:179-86.

19. Greene AK, May JW Jr. Applying to plastic surgery residency: Factors associated with medical student career choice. Plast Reconstr Surg 2008;121:1049-53.

20. Burd A, Chiu T, McNaught C. Plastic surgery in the undergraduate curriculum: the importance of considering students' perceptions. Br J Plast Surg 2004;57:773-9.

21. Patel MS, Khalsa B, Rama A, et al. Early intervention to promote medical student interest in surgery and the surgical subspecialties. J Surg Educ 2013;70:81-6.

22. Li R, Buxey K, Ashrafi A, Drummond KJ. Assessment of the role of a student-led surgical interest group in surgical education. J Surg Educ 2013;70:55-8.

23. Tribble C, Kern J, Smith M, DuBose J. The establishment of a surgical interest society for medical students. Am J Surg 2002;183:618-21.

24. Stroh DA, Ray-Mazumder N, Norman JA, et al. Influencing medical student education via a voluntary shadowing program for trauma and acute care surgery. JAMA Surg 2013;148:968-70.

25. Cloyd J, Holtzman D, O'Sullivan P, Sammann A, Tendick F, Ascher N. Operating room assist: Surgical mentorship and operating room experience for preclerkship medical students. J Surg Educ $2008 ; 65: 275-82$. 